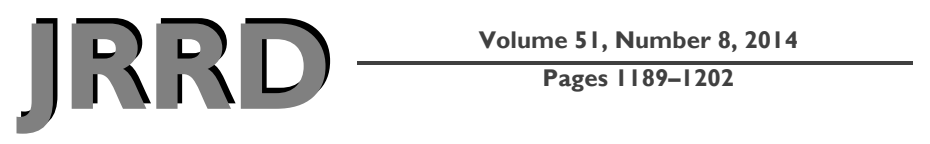

\title{
Correlates of pain symptoms among Iraq and Afghanistan military personnel following combat-related blast exposure
}

\author{
Kelcey J. Stratton, PhD; ${ }^{1-3^{*}}$ Sage E. Hawn, BS; ${ }^{3}$ Ananda B. Amstadter, PhD; ${ }^{3}$ David X. Cifu, MD; ${ }^{1,4}$ William C. \\ Walker, $\mathrm{MD}^{\mathbf{1 , 4}}$ \\ ${ }^{1}$ Hunter Holmes McGuire Department of Veterans Affairs Medical Center, Richmond, VA; ${ }^{2}$ Department of Psychology, \\ ${ }^{3}$ Virginia Institute for Psychiatric and Behavioral Genetics, and ${ }^{4}$ Department of Physical Medicine and Rehabilitation, \\ Virginia Commonwealth University, Richmond, VA
}

\begin{abstract}
Pain complaints are highly prevalent among military servicemembers and Veterans of the recent combat operations in Iraq and Afghanistan. The high comorbidity of pain with conditions such as posttraumatic stress disorder (PTSD) and traumatic brain injury (TBI) underscores the importance of a greater understanding of factors associated with complex polytraumatic injuries among military personnel. The present study aimed to identify correlates of current pain among 201 U.S. military personnel who reported at least one blast experience during combat deployment (age [mean +/- standard deviation]: 27.20 +/$7.58 \mathrm{yr}$ ). Theoretically derived subsets of variables were analyzed in successive hierarchical regression models to determine correlates of self-reported pain symptoms. Preliminary models evaluated demographic features, medical and injury characteristics (e.g., TBI classification), psychosocial history (e.g., trauma exposure), and psychiatric variables. A final model was then derived, in which older age, possible or probable mild TBI, depression symptoms, and PTSD re-experiencing symptoms emerged as significant correlates of pain. The findings further the understanding of polytrauma symptoms among military personnel by identifying specific patient characteristics and comorbidity patterns related to pain complaints. Increased awareness of demographic, psychiatric, or medical factors implicated in pain will enhance comprehensive clinical assessment and intervention efforts.
\end{abstract}

Key words: blast exposure, combat, depression, military, OIF/ OEF/OND, pain, polytrauma, posttraumatic stress disorder, trauma, traumatic brain injury.

\section{INTRODUCTION}

A growing literature supports a relationship between pain conditions and psychiatric disorders such as depression and posttraumatic stress disorder (PTSD). Pain and PTSD are particularly significant problems for military Veterans; up to 20 percent of returning Veterans meet criteria for PTSD [1-2], and moreover, data from a range of

\footnotetext{
Abbreviations: $\mathrm{ADHD}=$ attention deficit/hyperactivity disorder, $\mathrm{AOC}=$ alteration of consciousness, $\mathrm{BESQ}=$ Blast Experience Screening Questionnaire, CES-D = Centers for Epidemiologic Studies Depression Scale, DSM-IV = Diagnostic and Statistical Manual of Mental Disorders-4th Edition, ECMP = Events Checklist for Military Personnel, IED = improvised explosive device, $\mathrm{LOC}=$ loss of consciousness, OIF/OEF/OND = Operation Iraqi Freedom/Operation Enduring Freedom/Operation New Dawn, PCL = Posttraumatic Stress Disorder Checklist, PPCS = persistent postconcussive syndrome, $\mathrm{PTA}=$ posttraumatic amnesia, $\mathrm{PTSD}=$ posttraumatic stress disorder, SF-MPQ $=$ ShortForm McGill Pain Questionnaire, SM = servicemember, TBI = traumatic brain injury, VA = Department of Veterans Affairs, WRAMC BIQ = Walter Reed Army Medical Center Blast Injury Questionnaire.

*Address all correspondence to Kelcey J. Stratton, PhD; Hunter Holmes McGuire VA Medical Center, 1201 Broad Rock Blvd (116-B), Richmond, VA 23249; 804-675-5000, ext 2432; fax: 804-675-6853. Email: Kelcev.Stratton@va.gov http://dx.doi.org/10.1682/JRRD.2014.04.0111
} 
deployment eras suggest that up to 80 percent of Veterans seeking treatment for PTSD also experience pain [3-8]. Despite some differences in injury characteristics and pain locations that vary by deployment era, the results of previous work support a relationship between the presence and severity of PTSD symptoms and increased pain level and pain disability and poorer health outcomes among Veterans [3-4]. However, among the Active Duty servicemembers (SMs) and Veterans of Operation Iraqi Freedom/ Operation Enduring Freedom/Operation New Dawn (OIF/ OEF/OND), the association between pain and PTSD is further complicated by the sequelae of exposure to blasts, such as those caused by improvised explosive devices (IEDs), rocket-propelled grenades, and other explosive munitions [9]. Blast-related injuries have emerged as one of the chief concerns for returning military personnel, resulting in a devastating, complex array of outcomes that includes neurocognitive difficulties associated with traumatic brain injury (TBI), psychiatric disorders, and pain syndromes (e.g., Lew et al. [6] and Cifu et al. [10]). Indeed, the complexity of these combat-related injuries has led some researchers to suggest that a polytraumatic injury profile (i.e., the presence of multiple injuries) may best describe the negative health consequences associated with recent combat operations because returning SMs and Veterans tend to experience multiple medical problems [10]. Therefore, more study is needed to understand the unique risk factors and symptom comorbidity patterns in the context of polytraumatic injuries among OIF/OEF/ OND military personnel in order to best inform prevention and secondary intervention efforts, particularly as these individuals increasingly begin to transition from Active Duty military service and seek ongoing healthcare.

Recent studies of pain, PTSD, and blast-related neurocognitive difficulties, including TBI and persistent postconcussive syndrome (PPCS), have found high cooccurrence of these conditions among OIF/OEF/OND Veterans. Results from two studies of nationally representative samples of OIF/OEF/OND Veterans enrolled in Department of Veterans Affairs (VA) healthcare reveal high prevalence rates of psychiatric disorders $(9.5 \%-$ $42.0 \%)$ and pain complaints (20\%-33\%), with the prevalence of co-occurring PTSD and/or pain increasing significantly among Veterans with diagnosed TBI (54\%-73\%) [10-11]. Regarding specific polytrauma clinical samples, Lew et al. determined that the coprevalence rate of chronic pain, PTSD, and PPCS among OIF/OEF/OND Veterans was roughly 42 percent, indicating a high degree of comorbidity for these three conditions [6]. In fact, the results suggested a higher likelihood of having concurrent diagnoses for two or all of the disorders than of receiving a diagnosis for any individual condition alone. Additional research conducted in other Veteran and civilian samples likewise suggests that pain and PTSD [12] and pain and depression [13] are more likely to manifest as comorbidities rather than as individual conditions.

Etiologic models of pain and comorbid disorders purport a complex interaction of biological and psychosocial factors, and considering the heterogeneity of polytrauma injuries, findings regarding symptom development and comorbidity models are mixed. Moreover, a variety of psychosocial factors have been linked to pain and related conditions. Prevalence of pain symptoms and/or pain-related disability increases with age [14] and may also vary among other demographic characteristics such as education $[8,15]$, socioeconomic status [16], and sex $[8,17]$. Lifetime exposure to trauma and stress has been found to affect a variety of medical concerns, including lifetime prevalence of chronic pain, suggesting that exposure to stressful life events may be an important risk factor in the development of pain disorders [18-19]. For example, individuals with co-occurring PTSD and pain report higher rates of physical or sexual abuse history and more chronic medical conditions than persons with neither disorder and higher ratings of psychiatric distress than those individuals with pain or PTSD alone [19]. Among OIF/OEF/OND Veterans, diagnoses of mood disorders, PTSD, substance use disorders, anxiety disorders, TBI, and high body mass index were found to distinguish individuals with persistent (i.e., chronic) pain versus those with no pain [8]. However, other studies have not supported these risk and comorbidity models, suggesting that correlates of PTSD and pain symptoms are not fully understood. Despite finding substantial rates of positive PTSD, depression, and substance abuse screens in a sample of OIF/OEF/OND Veterans, Moeller-Bertram et al. did not find any demographic, physical health, or mental health differences between individuals who screened positive for PTSD only and those who screened positive for both PTSD and pain [20].

Although empirical studies of pain and associated biological, social, and psychological risk factors have provided some clues to the development and correlates of pain disorders, more information regarding these relationships within the context of polytraumatic injury and military samples is needed. Identification of factors associated with current pain symptoms, such as lifetime exposure to stress or levels of current psychiatric distress, may yield important insights about potential vulnerability and maintenance 
factors that could complicate the course of recovery following injury and the onset of pain conditions following combat. A better understanding of these factors in relation to the subjective experience of pain may be useful for both identifying those individuals at greatest risk for developing complex and persistent symptoms following combat and developing complementary treatment approaches that address the significant overlap in common polytraumatic injuries.

To this end, the purpose of this study was to examine demographic, psychosocial, and life history predictors of pain in a sample of U.S. military SMs who were exposed to a blast experience during their deployment and who may or may not meet criteria for TBI or PPCS. Specifically, this study aims to determine correlates of current, self-reported pain symptoms by analyzing the relationships between pain and conceptually similar categories of potential comorbidity factors; the selection of variables was informed by previous work in this area and includes analysis of demographic characteristics, blast exposure and injury history, lifetime traumatic event exposure, and psychiatric complaints. Although previous work has established the coprevalence of pain and conditions such as PTSD and TBI, these studies have largely focused on prevalence rates of clinical diagnoses rather than patients' experience of symptoms or additional psychosocial factors that may play a role in pain outcomes.

The present study extends previous work regarding polytrauma injury prevalence rates and aims to add clarity to the understanding of pain in the context of polytraumatic injury by determining the factors related to SMs' and Veterans' subjective pain experience. Findings regarding the relative effect of various demographic, psychosocial, and medical and injury characteristics on pain symptoms among OIF/OEF/OND Veterans have been mixed, and this study is unique in that a broad range of variables as potential correlates of current pain symptoms is available for examination. Moreover, while the majority of previous studies has relied on treatment-seeking VA samples, the present study sample consists of both Active Duty SMs and Veterans recruited from a variety of clinical and nonclinical locations, thereby potentially increasing generalizability of the findings. We hypothesized that greater exposure to traumatic life events; more significant and complex medical history, including history of TBI; and greater psychiatric symptoms would be associated with increased self-reported pain complaints.

\section{METHODS}

Data were collected as part of a Congressionally Directed Medical Research Program investigating blast exposure and injuries sustained during OIF/OEF/OND. Eligible military SMs and Veterans had a blast experience within the past $2 \mathrm{yr}$ while deployed in OIF/OEF/ OND. The data analyzed in the current article represent one aspect of a larger multipart study that includes cognitive, balance, and electroencephalography testing of participants as well as planned longitudinal follow-up of participants over the course of $1 \mathrm{yr}$ [21-22].

\section{Procedure}

All participants completed a series of self-report questionnaires. Although some participants were enrolled at clinics, the research evaluations were separate from clinical care or compensation and pension processes. Research staff supervised completion of all the questionnaires and provided additional instructions as needed. Participants received nominal compensation for their time and effort.

\section{Participants}

SMs and Veterans were eligible if they had a blast experience within the past 2 yr while deployed in OIF/ OEF/OND. Participants were recruited via letters and advertisements and from ambulatory healthcare clinics at a mid-Atlantic VA medical center and at several Army and Marine Corps bases located in the mid-Atlantic region of the United States. Blast experience was defined as having any of the following symptoms or experiences occurring during or shortly after exposure to blast or explosion: were dazed or confused; saw stars; experienced headache, dizziness, irritability, memory gap (not remembering injury or injury period), hearing loss, abdominal pain, or shortness of breath; struck by debris; knocked over or down; knocked into or against something; had helmet damaged; or were medically evacuated. Individuals who reported symptoms suggestive of possible severe or moderate TBI were excluded from the present study $(n=4)$; thus, participants who may have sustained a TBI during their blast experience were considered to be in the mild TBI category. Severe or moderate TBI was defined as more than $30 \mathrm{~min}$ of lost consciousness, brain bleeding or blood clot (i.e., abnormal brain computed tomography scan), or amnesia for the first $\geq 24 \mathrm{~h}$ after the event. At the closure of study enrollment, 238 participants passed the eligibility prescreening and consented for study procedures. Of these, 
22 participants either did not meet final eligibility criteria or failed to complete the initial study evaluations, resulting in the final enrollment sample size of 216. At the time of the present analyses, data had been collected and authenticated for the first 201 participants who met study criteria.

\section{Measures}

\section{Short-Form McGill Pain Questionnaire}

The Short-Form McGill Pain Questionnaire (SFMPQ) pain rating scale consists of 15 pain descriptors (11 sensory, 4 affective) that are rated for intensity on a Likert scale from 0 (none) to 3 (severe) [23]. The scale yields three pain scores: a total pain score, which is a sum of all 15 items, and sensory and affective pain subscale scores. The total pain score is frequently used in research and clinical applications, with higher scores indicating greater severity of current pain symptoms. The SF-MPQ has been shown to have strong psychometric properties, and it is sensitive to changes in pain scores over time and/ or as a result of clinical intervention [23]. Internal consistency for the total SF-MPQ score in the current sample was good (Cronbach $\alpha=0.86$ ).

\section{Prior Health and Demographics Questionnaire}

A detailed health and demographics questionnaire was developed for the study. Questions assessed for basic demographic information (e.g., sex, age, marital status, race/ethnicity, education, military history) as well as selected psychiatric and medical history. Psychiatric questions asked whether the participant had ever been prescribed medications for a behavioral, emotional, or thought disorder and whether he or she had ever received school help for conditions such as attention deficit/hyperactivity disorder (ADHD) or a learning disability. These questions were dichotomized (yes/no) for the statistical analysis. The medical questions included thorough assessment of concussions and/or head injuries that occurred either prior to the OIF/OEF/OND tour(s) or during deployment that were not related to a blast experience.

\section{Blast Experience Screening Questionnaire}

Participants were queried on their traumatic blast experience(s) via the Blast Experience Screening Questionnaire (BESQ), which was developed for a larger epidemiologic study of blast exposures. The BESQ was adapted from the Walter Reed Army Medical Center Blast Injury Questionnaire (WRAMC BIQ) [24]. The WRAMC
BIQ screens patients for previously unreported blastrelated pathologic conditions via 19 questions regarding the blast itself, as well as pre- and postblast symptoms including the presence of visual disturbances, headaches, dizziness, or hearing loss; distance from the blast; and degree of cover. The BESQ focuses on symptoms immediately after the blast exposure and also inquires about alterations of consciousness (AOCs) following the blast. The AOC questions were designed to assess three specific aspects of postblast severity: memory gap, observerreported loss of consciousness (LOC), and continuous memory. Participants are asked to provide information on up to three separate blast events. In accordance with previous work with this scale [21], responses from the selected AOC questions indicating posttraumatic amnesia (PTA) or LOC were combined to create a categorical index of three potential diagnostic groups of mild TBI: definite or probable TBI (2 or 3 positive AOC items), possible TBI (1 positive AOC item), and no evidence of TBI with either PTA or LOC (all 3 AOC items negative).

\section{Trauma Exposure History}

The Events Checklist for Military Personnel (ECMP) is a questionnaire developed specifically for this study that was used to identify distressing combat and noncombat events that met the Diagnostic and Statistical Manual of Mental Disorders-4th Edition (DSM-IV) criterion A for PTSD (qualifying stressor). The ECMP differs from other traumatic events questionnaires in that items pertaining to combat events are listed separately from noncombat events [25-26]. Although other trauma account measures have specific categories for warfare and/or combat, these measures offer limited detail about combat experiences, and there may be some confusion about incidents that may fit multiple categories (e.g., motor vehicle accident or injury during combat). Thus, the ECMP was developed for the present study as a tool to provide improved description of the specific combatrelated trauma experiences reported by participants.

The 11-item combat experiences portion of the questionnaire queried for yes or no answers to nine specific combat experiences (e.g., "Witnessed the serious injury or death of enemy troops," "Experienced an IED that was detonated"), one question that queried for "Other combatrelated event," and one question that asked "Have you had any combat-related experiences like these that you feel you can't tell about?” A summary score of all affirmative answers yielded a total combat experiences score. 
Participants were also asked to respond yes or no to potentially traumatic events that occurred outside of combat. Thirteen specific events (e.g., "Been a victim of a violent crime," "Experienced physical abuse from a family member, caretaker, or teacher") were queried, as well as questions for "Other" and "Have you had any other distressing or disturbing events that you feel you can't tell about?” Affirmative responses were summed to create a total noncombat traumatic experiences score. For both the combat and noncombat experiences, participants were asked to identify their most distressing combat and noncombat event; to report details related to that event, including emotional response to the event; and to rate their peritraumatic level of distress and their current level of distress on a Likert scale from 0 (not at all) to 7 (extremely).

\section{Centers for Epidemiologic Studies Depression Scale}

The Centers for Epidemiologic Studies Depression Scale (CES-D) is a brief self-report scale designed to assess depressive symptoms in the general population [27]. The 20-item scale focuses on the affective component of depression and is not designed to be sufficient for a clinical diagnosis of a major depressive episode; however, the CES-D is highly correlated with clinical ratings of depression and other related complaints. A cutoff score of 16 is indicative of significant depressive symptomatology. The scale has been well-validated in both clinical and general samples, and internal consistency in the current sample was excellent (Cronbach $\alpha=0.89$ ). The total score was used as a continuous variable in the analyses.

\section{Posttraumatic Stress Disorder Checklist}

The Posttraumatic Stress Disorder Checklist (PCL) is a 17-item self-report measure of the 17 DSM-IV symptoms of PTSD [28]. Respondents are asked, "In the past month, how much have you been bothered by ...” each symptom, rated on a Likert scale from 1 (not at all) to 5 (extremely). In the current study, scores were calculated for each of the three PTSD symptom clusters (re-experiencing, avoidance/ numbing, hyperarousal), and each criterion score was examined in relation to pain, given past studies showing differential relationships between pain and PTSD subscales $[3,29]$. A total scale cutoff score of 50 is recommended in military samples as an indicator of significant PTSD symptomatology. Internal consistency for each of the three PCL subscale scores in the current sample was good (Cronbach $\alpha=0.83-0.86$ ).

\section{Statistical Analyses}

The demographic, SF-MPQ, selected blast experience and TBI, trauma exposure history, PCL, and CES-D data were first analyzed with descriptive statistics in order to summarize the sample characteristics. A series of hierarchical regression analyses was then conducted to analyze defined clusters of variables as correlates of pain. Hierarchical models were conducted in order to best determine the relative contribution of each variable at each stage of the model. Four theoretically derived predictor sets were chosen, and one regression was conducted for each predictor set: (1) demographics (i.e., age, race, marital status, education); (2) medical, blast, and injury characteristics (i.e., history of psychiatric medication, history of ADHD or learning disorder, number of prior head injuries, number of deployment blast exposures, classification of combat-related TBI); (3) lifetime trauma exposure characteristics (i.e., total number of combat-related trauma exposures, peritraumatic and current ratings of distress related to worst combat trauma, total number of noncombat trauma exposure, peritraumatic and current ratings of distress related to worst noncombat trauma); and (4) psychiatric variables (i.e., depression, PTSD symptom clusters). Any significant variable from the preliminary regression models was then entered into a final regression model. The total score on the SF-MPQ was the dependent variable for each of the preliminary analyses and the final model.

\section{RESULTS}

The sample consisted of 194 men and 7 women who were $27.20 \pm 7.58 \mathrm{yr}$ old (mean \pm standard deviation). Many of the participants reported more than one deployment location. Table 1 presents descriptive characteristics of the sample. The sample was exposed to a high number of both combat $(7.67 \pm 1.93)$ and noncombat $(3.52 \pm 2.01)$ potentially traumatic event types. The respondents reported high levels of PTSD and depression symptomatology, with the total PCL and CES-D scores (47.54 \pm 14.67 and $17.95 \pm 10.44$, respectively) nearing or meeting criteria for clinically significant distress. Using the diagnostic categorization of TBI based on AOC responses, 45 participants were considered to have possible TBI and 66 participants were categorized as probable TBI, with the remaining 90 participants reporting no PTA or LOC following blast exposure. Participants reported an average 
Table 1.

Descriptive characteristics of sample $(N=201)$.

\begin{tabular}{|c|c|}
\hline Characteristic & $\begin{array}{c}n(\%) \text { or } \\
\text { Mean } \pm \text { SD }\end{array}$ \\
\hline \multicolumn{2}{|l|}{$\overline{\text { Sex }}$} \\
\hline Female & $7(3.5)$ \\
\hline Male & $194(96.5)$ \\
\hline \multicolumn{2}{|l|}{ Race } \\
\hline White/Caucasian & $160(79.6)$ \\
\hline Black/African American & $29(14.4)$ \\
\hline Other & $12(6.0)$ \\
\hline \multicolumn{2}{|l|}{ Marital Status } \\
\hline Single & $92(45.8)$ \\
\hline Married & $91(45.3)$ \\
\hline Divorced & $18(9.0)$ \\
\hline \multicolumn{2}{|l|}{ Education } \\
\hline Less Than High School & $2(1.0)$ \\
\hline High School & $105(52.2)$ \\
\hline Some College & 69 (34.3) \\
\hline College Graduate & $22(10.9)$ \\
\hline Postgraduate Degree & $3(1.5)$ \\
\hline \multicolumn{2}{|l|}{ Highest Rank } \\
\hline E1-E4 & 119 (59.2) \\
\hline E5-E7 & 67 (33.3) \\
\hline E8-E9 & $2(1.0)$ \\
\hline W1-W5 & $2(1.0)$ \\
\hline O1-O9 & $9(4.5)$ \\
\hline Other & $2(1.0)$ \\
\hline \multicolumn{2}{|l|}{ Deployment Locations* } \\
\hline \multicolumn{2}{|l|}{ Operation Enduring Freedom } \\
\hline 1 Deployment & $114(-)$ \\
\hline 2 Deployments & $30(-)$ \\
\hline \multicolumn{2}{|l|}{ Operation Iraqi Freedom } \\
\hline 1 Deployment & $68(-)$ \\
\hline 2 Deployments & $27(-)$ \\
\hline 3+ Deployments & $9(-)$ \\
\hline Other Deployment Location & $31(-)$ \\
\hline \multicolumn{2}{|l|}{ Branch of Service ${ }^{*}$} \\
\hline Army & $83(-)$ \\
\hline Navy & $4(-)$ \\
\hline Air Force & $2(-)$ \\
\hline Marine Corps & $114(-)$ \\
\hline Short-Form McGill Pain Questionnaire (score) & $11.04 \pm 7.82$ \\
\hline
\end{tabular}

SF-MPQ total score of $11.04 \pm 7.82$, indicating moderate levels of pain severity that are consistent with the scale's validation samples [23]. Head ( $n=131)$, lower back $(n=$ $91)$, and knee $(n=58)$ pain were the most commonly reported pain areas, followed by pain in the neck $(n=37)$, mid-back ( $n=32)$, shoulder $(n=32)$, ankle $(n=19)$, and hip $(n=16)$ regions. Table 2 presents full results of each of the preliminary hierarchical linear regressions.

\section{Demographics}

Due to the small number of women in the sample, sex was not analyzed as a separate variable. From the demographic model, only older age was significantly related to pain severity $\left(\mathrm{F}(8,192)=3.02, \mathrm{R}^{2}=0.11, p<\right.$ 0.01 ), accounting for a relatively small amount of variance in the model. None of the other variables from this model were statistically significant.

\section{Medical/Blast/Injury History}

As shown in Table 2, higher number of deployment blast exposures and more severe TBI classification were related to pain severity. In the overall regression model $\left(F(6,194)=5.01, R^{2}=0.13, p<0.001\right)$, a TBI classification of possible or probable TBI was associated with higher pain severity ratings.

\section{Trauma Exposure}

Results from model 3 supported a relationship between higher ratings of current distress to the worst combatrelated trauma and pain severity at the final step of the model $\left(F(6,193)=6.24, R^{2}=0.16, p<0.001\right)$.

\section{Psychiatric Variables}

Higher CES-D total score and higher scores on the PCL re-experiencing symptom cluster were associated with pain severity in model $4\left(F(4,196)=18.64, R^{2}=\right.$ 0.28, $p<0.001)$. Compared with the results of the first three preliminary regression models, depression and PTSD re-experiencing symptoms appeared to account for a much larger proportion of variance in pain symptoms.

\section{Final Model}

Following the series of preliminary regression models, the significant predictors of age, number of deployment blast exposures, TBI classification, current rating of distress to the identified worst combat-related trauma, CES-D total score, and PCL re-experiencing subscale score were entered hierarchically into the final predictor set. In the 
Table 2.

Successive hierarchical linear regression models investigating demographics; medical, blast, and injury history; trauma exposure; and psychiatric variables as predictors of Short-Form McGill Pain Questionnaire ratings $(N=201)$.

\begin{tabular}{|c|c|c|c|c|c|c|c|c|c|c|c|c|c|c|c|}
\hline \multirow{2}{*}{ Demographics } & \multicolumn{3}{|c|}{ Model 1} & \multicolumn{3}{|c|}{ Model 2} & \multicolumn{3}{|c|}{ Model 3} & \multicolumn{3}{|c|}{ Model 4} & \multicolumn{3}{|c|}{ Model 5} \\
\hline & $\mathrm{B} \pm \mathrm{SE}(\mathrm{B})$ & $\beta$ & $t$ & $B \pm \mathrm{SE}(B)$ & $\beta$ & $t$ & $B \pm \mathrm{SE}(\mathrm{B})$ & $\beta$ & $t$ & $B \pm \mathrm{SE}(\mathrm{B})$ & $\beta$ & $t$ & $B \pm \mathrm{SE}(\mathrm{B})$ & $\beta$ & $t$ \\
\hline Age (yr) & $0.30 \pm 0.07$ & $0.29^{*}$ & 4.27 & $0.26 \pm 0.08$ & $0.25^{*}$ & 3.41 & $0.29 \pm 0.08$ & $0.28^{*}$ & 3.68 & $0.32 \pm 0.09$ & $0.31^{*}$ & 3.60 & - & - & - \\
\hline Married & - & - & - & $1.52 \pm 1.20$ & 0.10 & 1.27 & $1.28 \pm 1.20$ & 0.08 & 1.07 & $1.25 \pm 1.21$ & 0.08 & 1.04 & - & - & - \\
\hline Divorced & - & - & - & $1.02 \pm 2.01$ & 0.04 & 0.51 & $1.04 \pm 2.01$ & 0.04 & 0.52 & $0.94 \pm 2.03$ & 0.03 & 0.46 & - & - & - \\
\hline $\begin{array}{c}\text { Black/African } \\
\text { American }\end{array}$ & - & - & - & - & - & - & $-2.85 \pm 1.54$ & -0.13 & -1.85 & $-2.78 \pm 1.54$ & -0.13 & -1.88 & - & - & - \\
\hline Other & - & - & - & - & - & - & $-0.89 \pm 2.25$ & -0.03 & -0.39 & $-0.92 \pm 2.27$ & -0.03 & -0.45 & - & - & - \\
\hline $\begin{array}{l}\text { Education }(0=\text { High } \\
\text { School })\end{array}$ & & & & & & & & & & & & & & & \\
\hline Some College & - & - & - & - & - & - & - & - & - & $-0.54 \pm 1.22$ & -0.03 & -0.45 & - & - & - \\
\hline \multirow{2}{*}{$\begin{array}{c}\text { Medical/Blast/Injury } \\
\text { History }\end{array}$} & \multicolumn{3}{|c|}{ Model 1} & \multicolumn{3}{|c|}{ Model 2} & \multicolumn{3}{|c|}{ Model 3} & \multicolumn{3}{|c|}{ Model 4} & \multicolumn{3}{|c|}{ Model 5} \\
\hline & $\mathrm{B} \pm \mathrm{SE}(\mathrm{B})$ & $\beta$ & $t$ & $\mathrm{~B} \pm \mathrm{SE}(\mathrm{B})$ & $\beta$ & $t$ & $B \pm \mathrm{SE}(\mathrm{B})$ & $\beta$ & $t$ & $B \pm \mathrm{SE}(\mathrm{B})$ & $\beta$ & $t$ & $\mathrm{~B} \pm \mathrm{SE}(\mathrm{B})$ & $\beta$ & $t$ \\
\hline Past Medication & $2.37 \pm 1.20$ & 0.14 & $1.97^{\dagger}$ & $2.37 \pm 1.21$ & $0.14^{\dagger}$ & 1.96 & $2.46 \pm 1.21$ & $0.14^{\dagger}$ & 2.03 & $1.85 \pm 1.22$ & 0.11 & 1.52 & $2.28 \pm 1.19$ & 0.13 & 1.92 \\
\hline ADHD/Learning & - & - & - & $-0.09 \pm 1.98$ & 0.00 & -0.05 & $0.10 \pm 1.98$ & 0.00 & 0.05 & $0.18 \pm 1.96$ & 0.01 & 0.09 & $0.54 \pm 1.89$ & 0.02 & 0.29 \\
\hline $\begin{array}{l}\text { No. of Prior } \\
\text { Head Injuries }\end{array}$ & - & - & - & - & - & - & $1.45 \pm 1.16$ & 0.09 & 1.25 & $-1.64 \pm 1.15$ & -0.10 & -1.43 & $-1.63 \pm 1.11$ & -0.10 & -1.47 \\
\hline $\begin{array}{l}\text { No. of Blast } \\
\text { Exposures }\end{array}$ & - & - & - & - & - & - & - & - & - & $0.70 \pm 0.27$ & $0.18^{\dagger}$ & 2.54 & $0.84 \pm 0.27$ & $0.22^{\dagger}$ & 3.15 \\
\hline $\begin{array}{l}\text { TBI Classification } \\
\quad(0=\text { No Evidence })\end{array}$ & & & & & & & & & & & & & & & \\
\hline Possible TBI & - & - & - & - & - & - & - & - & - & - & - & - & $3.87 \pm 1.36$ & $0.21^{\dagger}$ & 2.84 \\
\hline $\begin{array}{l}\text { Distress at Time } \\
\text { of Worst } \\
\text { Combat Trauma }\end{array}$ & - & - & - & $0.03 \pm 0.31$ & 0.01 & 0.10 & $0.06 \pm 0.31$ & 0.01 & 0.18 & $-0.07 \pm 0.32$ & -0.02 & -0.23 & - & - & - \\
\hline $\begin{array}{l}\text { Current Distress } \\
\text { to Worst } \\
\text { Combat Trauma }\end{array}$ & - & - & - & $1.44 \pm 0.29$ & $0.37^{*}$ & 5.05 & $1.41 \pm 0.29$ & $0.36^{*}$ & 4.89 & $1.39 \pm 0.29$ & $0.35^{*}$ & 4.85 & - & - & - \\
\hline $\begin{array}{l}\text { Total Noncombat } \\
\text { Traumas }\end{array}$ & - & - & - & - & - & - & $0.17 \pm 0.19$ & 0.06 & 0.90 & $0.26 \pm 0.20$ & 0.09 & 1.30 & - & - & - \\
\hline $\begin{array}{l}\text { Distress at Time } \\
\text { of Worst } \\
\text { Noncombat Trauma }\end{array}$ & - & - & - & - & - & - & - & - & - & $0.46 \pm 0.32$ & 0.14 & 1.44 & - & - & - \\
\hline $\begin{array}{l}\text { Current Distress } \\
\text { at Worst } \\
\text { Noncombat Trauma }\end{array}$ & - & - & - & - & - & - & - & - & - & $0.13 \pm 0.26$ & 0.05 & 0.50 & - & - & - \\
\hline$R^{2} / \Delta R^{2}$ & 0.00 & $/ 0.00$ & & 0.13 & $3 / 0.13$ & & 0.13 & 3/0.00 & & 0.16 & $6 / 0.03$ & & & - & \\
\hline$\Delta F$ & & 64 & & & $.37^{*}$ & & & .81 & & & $.25^{\dagger}$ & & & - & \\
\hline
\end{tabular}


Table 2. (cont)

Successive hierarchical linear regression models investigating demographics; medical, blast, and injury history; trauma exposure; and psychiatric variables as predictors of Short-Form McGill Pain Questionnaire ratings $(N=201)$.

\begin{tabular}{|c|c|c|c|c|c|c|c|c|c|c|c|c|c|c|c|}
\hline \multirow{2}{*}{ Psychiatric Variables } & \multicolumn{3}{|c|}{ Model 1} & \multicolumn{3}{|c|}{ Model 2} & \multicolumn{3}{|c|}{ Model 3} & \multicolumn{3}{|c|}{ Model 4} & \multicolumn{3}{|c|}{ Model 5} \\
\hline & $\mathrm{B} \pm \mathrm{SE}(\mathrm{B})$ & $\beta$ & $t$ & $\mathrm{~B} \pm \mathrm{SE}(\mathrm{B})$ & $\beta$ & $t$ & $\mathrm{~B} \pm \mathrm{SE}(\mathrm{B})$ & $\beta$ & $t$ & $\mathrm{~B} \pm \mathrm{SE}(\mathrm{B})$ & $\beta$ & $t$ & $\bar{B} \pm \mathrm{SE}(\mathrm{B})$ & $\beta$ & $t$ \\
\hline$\overline{\text { CES-D Total }}$ & $0.35 \pm 0.05$ & $0.47^{*}$ & 7.52 & $0.24 \pm 0.06$ & $0.32^{*}$ & 4.36 & $0.19 \pm 0.07$ & $0.26^{\dagger}$ & 2.88 & $0.20 \pm 0.07$ & $0.27^{\dagger}$ & 2.93 & - & - & - \\
\hline $\begin{array}{l}\text { PCL Criterion B: } \\
\text { Re-experiencing }\end{array}$ & - & - & - & $0.43 \pm 0.12$ & $0.26^{*}$ & 3.58 & $0.35 \pm 0.14$ & $0.21^{\dagger}$ & 2.56 & $0.39 \pm 0.15$ & $0.24^{\dagger}$ & 2.57 & - & - & - \\
\hline $\begin{array}{l}\text { PCL Criterion C: } \\
\text { Avoidance }\end{array}$ & - & - & - & - & - & - & $0.15 \pm 0.12$ & 0.13 & 1.27 & $0.16 \pm 0.12$ & 0.14 & 1.37 & - & - & - \\
\hline $\begin{array}{l}\text { PCL Criterion D: } \\
\text { Hyperarousal }\end{array}$ & - & - & - & - & - & - & - & - & - & $-0.09 \pm 0.15$ & -0.06 & -0.60 & - & - & - \\
\hline$R^{2} / \Delta R^{2}$ & \multicolumn{3}{|c|}{$0.22 / 0.22$} & \multicolumn{3}{|c|}{$0.27 / 0.05$} & \multicolumn{3}{|c|}{$0.27 / 0.01$} & \multicolumn{3}{|c|}{$0.28 / 0.00$} & \multicolumn{3}{|c|}{-} \\
\hline$\Delta F$ & \multicolumn{3}{|c|}{$56.49^{*}$} & \multicolumn{3}{|c|}{$12.79^{*}$} & \multicolumn{3}{|c|}{1.61} & \multicolumn{3}{|c|}{0.35} & \multicolumn{3}{|c|}{-} \\
\hline
\end{tabular}

${ }^{*} p<0.01$.

${ }^{\dagger} p<0.05$.

ADHD = attention deficit/hyperactivity disorder, CES-D = Centers for Epidemiologic Studies Depression Scale, PCL = Posttraumatic Stress Disorder Checklist, $\mathrm{SE}=$ standard error, $\mathrm{TBI}=$ traumatic brain injury

final model (Table 3), the variables of older age, the classification of possible or probable mild TBI, higher CES-D total score, and higher scores on the PCL re-experiencing symptom cluster remained significant correlates of SFMPQ total score in the final step of the model $(\mathrm{F}(7,193)=$ $14.80, \mathrm{R}^{2}=0.35$, adjusted $\mathrm{R}^{2}=0.33, p<0.001$ ). The variables in the final model thus accounted for approximately one-third of the variance in current pain symptoms.

\section{DISCUSSION}

The purpose of this study was to explore the correlates of self-reported pain severity in a sample of blast-exposed OIF/OEF/OND military SMs and Veterans. A number of complex psychiatric, cognitive, and physical symptoms may be associated with combat-related blasts, and the high occurrence of polytraumatic injuries among returning military personnel emphasizes the need for a more complete understanding of variables that are associated with pain, particularly those that are potentially modifiable. Findings from the current study demonstrated a number of demographic, historical, and psychological factors that are related to current self-reported pain, namely older age, possible or probable mild TBI with PTA or LOC, depression symptoms, and the re-experiencing symptoms of PTSD. This study builds on previous work by systematically analyzing theoretically similar subsets of potential pain correlates that encompassed a broad range of demographics, medical history, TBI characteristics, lifetime trauma exposure, and psychiatric symptoms. Our results are consistent with Higgins et al.'s [8] study of persistent pain symptoms in OIF/OEF/OND Veterans and suggest that similar risk factors play a role in current pain symptoms as in chronic pain complaints. Thus, the present study broadens the knowledge of patient factors and comorbid conditions associated with subjective pain complaints in both Active Duty military and Veteran samples; this knowledge is important for identifying individual difference factors that may be implicated in pain symptoms, and the results may be used to inform assessment and intervention efforts for pain conditions.

As expected, psychiatric symptoms associated with depression and PTSD emerged as significant correlates of pain. While the present findings are in line with prior research demonstrating an association between depression and pain (e.g, Bair et al. [13]), the association between PTSD and pain is less clearly understood in the current literature. In this study, the re-experiencing symptoms of PTSD were the only symptom cluster that demonstrated a statistically significant association with pain. Past work on PTSD symptom clusters and pain has shown mixed results. For example, Burris et al. found that the re-experiencing symptom cluster was not related to pain severity in an adult orofacial pain sample [30]; rather, the avoidance and numbing cluster appeared to predict pain disability and severity through an association with depression symptoms. However, other work has supported a relationship between re-experiencing symptoms and pain in Veteran samples [3,29,31]. Notably, in a 
STRATTON et al. Pain and polytraumatic injury following combat

Table 3.

Final hierarchical linear regression model with only significant predictors from previous analyses as predictors of Short-Form McGill Pain Questionnaire ratings $(N=201)$.

\begin{tabular}{|c|c|c|c|c|c|c|c|c|c|c|c|c|c|c|c|c|c|}
\hline \multirow{2}{*}{$\begin{array}{l}\text { Demographic } \\
\text { Variables }\end{array}$} & \multicolumn{3}{|c|}{ Model 1} & \multicolumn{3}{|c|}{ Model 2} & \multicolumn{3}{|c|}{ Model 3} & \multicolumn{3}{|c|}{ Model 4} & \multicolumn{3}{|c|}{ Model 5} & \multicolumn{2}{|l|}{ Model 6} \\
\hline & $\mathrm{B} \pm \mathrm{SE}(\mathrm{B})$ & $\beta$ & $t$ & $\mathrm{~B} \pm \mathrm{SE}(\mathrm{B})$ & $\beta$ & $t$ & $\mathrm{~B} \pm \mathrm{SE}(\mathrm{B})$ & $\beta$ & $t$ & $\mathrm{~B} \pm \mathrm{SE}(\mathrm{B})$ & $\boldsymbol{\beta}$ & $t$ & $B \pm \mathrm{SE}(\mathrm{B})$ & $\beta$ & $t$ & $\mathrm{~B} \pm \mathrm{SE}(\mathrm{B}) \quad \beta$ & $t$ \\
\hline$\overline{\text { Age }}$ & $0.30 \pm 0.070$ & $0.29^{*}$ & 4.27 & $0.27 \pm 0.07$ & $0.26^{*}$ & 3.71 & $0.29 \pm 0.07 \mathrm{C}$ & $0.28^{*}$ & 4.07 & $0.25 \pm 0.07$ & $0.24^{*}$ & 3.65 & $0.18 \pm 0.07$ & $0.18^{\dagger}$ & 2.81 & $0.18 \pm 0.070 .18^{\dagger}$ & 2.84 \\
\hline $\begin{array}{l}\text { No. of Blast } \\
\text { Exposures }\end{array}$ & - & - & - & $0.50 \pm 0.27$ & 0.13 & 1.88 & $0.65 \pm 0.26 c$ & $0.17^{\dagger}$ & 2.49 & $0.46 \pm 0.26$ & 0.12 & 1.79 & $0.45 \pm 0.24$ & 0.12 & 1.85 & $0.44 \pm 0.240 .11$ & 1.83 \\
\hline \multicolumn{18}{|l|}{$\begin{array}{l}\text { TBI Classification } \\
\quad(0=\text { No } \\
\text { Evidence })\end{array}$} \\
\hline Probable TBI & - & - & - & - & - & - & $4.89 \pm 1.18$ & $0.29^{*}$ & 4.15 & $3.54 \pm 1.20$ & $0.21^{\dagger}$ & 2.94 & $3.16 \pm 1.13$ & $0.19^{\dagger}$ & 2.79 & $3.34 \pm 1.120 .20^{\dagger}$ & 3.00 \\
\hline $\begin{array}{l}\text { Current Distress to } \\
\text { Worst Trauma }\end{array}$ & - & - & - & - & - & - & - & - & - & $0.96 \pm 0.27$ & $0.25^{*}$ & 3.62 & $0.44 \pm 0.27$ & 0.11 & 1.65 & $0.09 \pm 0.290 .02$ & 0.31 \\
\hline CES-D Total & - & - & - & - & - & - & - & - & - & - & - & - & $0.26 \pm 0.05$ & $0.35^{\dagger}$ & 5.23 & $0.20 \pm 0.050 .27^{*}$ & 3.65 \\
\hline $\begin{array}{l}\text { PCL Criterion B: } \\
\text { Re-experiencing }\end{array}$ & - & - & - & - & - & - & - & - & - & - & - & - & - & - & - & $0.35 \pm 0.130 .21^{\dagger}$ & 2.68 \\
\hline
\end{tabular}

sample of female Veterans, Asmundson et al. found a particular association between re-experiencing symptoms and severe headache and migraine pain and suggested that headaches may function as a somatic flashback, thereby affecting the re-experiencing symptoms [29,32]. Similarly, findings from investigations of pain and PTSD in Veterans theorize that pain symptoms may serve as actual or symbolic reminders of traumatic experiences (e.g., Beckham et al. [3]). This association may be particularly salient when physical injuries are sustained alongside psychological injury, such as in the case of direct combat or a severe accident, and this finding may have important considerations for polytrauma rehabilitation. Therapies focused on restoring physical functioning and addressing areas of pain may inadvertently trigger distressing memories or emotions related to a traumatic event, and comprehensive rehabilitation approaches must consider the potential interdependence of these conditions. Future studies of interventions for PTSD and pain have the potential to reveal insights on the etiology of these co-occurring conditions by measuring the effects of treatment on one condition (i.e., PTSD) and assessing the potential symptom change of the other (i.e., pain).

Findings also supported the role of severity of exposure to physical or psychological potentially traumatic events, rather than breadth, in the association with pain symptoms. Total number of types of combat-related or noncombat potentially traumatic events was not signifi- cantly related to pain ratings; however, reported current emotional distress to the worst combat-related traumatic event emerged as a significant correlate of pain in a preliminary regression model. This association did not hold in the final regression model, which may be due to the high correlation between PTSD ratings and the current distress rating (Pearson $r$ coefficients $=0.48-0.58, p<$ 0.001 ), indicating that combat trauma-related distress was better accounted for by reported PTSD re-experiencing symptoms. Similarly, the total number of deployment blast exposures did not predict pain in the final model, but rather severity of effects potentially associated with these events, as determined by categorizations of possible or probable TBI. These findings are consistent, in part, with dose-response models of psychopathology following trauma exposure, in which the magnitude of an individual trauma or the cumulative effect of many traumas over the lifespan predict adjustment difficulties [33]. Although the relationship between past trauma exposure and pain has been supported in the literature (e.g., Sledjeski et al. [18]), less is known about the effect of repeated or severe trauma exposures on pain symptoms. This study offers important preliminary support for the relationship between severity of blast exposure characteristics and the degree of psychiatric distress related to trauma exposures on ratings of pain severity, rather than mere frequency of previous potentially traumatic event exposures. 
It is noteworthy that although the focus of the current study was blast-related exposures, pain conditions among OIF/OEF/OND Veterans may not always result directly from a blast exposure, but rather from other types of combat-related injuries, such as gunshot wounds and injuries resulting from motor vehicle accidents or from the cumulative effects of challenging field conditions (e.g., carrying heavy body armor and supplies) and multiple redeployments [34]. While TBI is perhaps one of the better known conditions reported among OIF/OEF/OND Veterans, with over 280,000 diagnosed cases since 2000 [35], recent reports by the Veterans Health Administration indicate that diseases of the musculoskeletal system are, in fact, among the most common diagnoses among those who have served in OIF/OEF/OND and are seeking VA healthcare [36]. Musculoskeletal system complaints frequently include a variety of pain complaints, and head, neck, back, shoulder, and knee pain have been found to be the most common pain complaints for those who served during OIF/OEF/OND [6]; findings from the current study are consistent with these reports. While the current study did not query the exact etiology or timing of the pain symptoms reported by the military personnel in our sample, the association between more severe TBI characteristics and pain complaints represents an area for more nuanced study; for example, more severe TBI characteristics may indicate greater blast exposure and injury, which directly results in increased pain due to the physical injury, or the relationship between TBI characteristics and pain may be mediated by a third variable, such as PTSD symptoms or musculoskeletal injuries. Longitudinal studies are needed to explore the interplay of these co-occurring symptoms across time in relation to discrete life events, such as blast and/or other potentially traumatic event exposures and physical injuries. Notably, a number of reports suggest that chronic pain is greater in patients with mild TBI than in those with moderate or severe TBI (see Nampiaparampil for a review [37]). However, this finding may be complicated by the fact that individuals with severe TBI may be less able to effectively communicate their pain experience [38]. Our results suggest that more severe characteristics of mild TBI are associated with reported pain symptoms, but it is possible that this relationship may only be worsened up until a certain point.

These findings hold potentially important implications for clinical interventions for pain and co-occurring psychiatric and medical conditions in returning Veterans. To begin, consistent with previous work conducted among OIF/OEF/OND Veterans, these data demonstrate an extensive number of returning OIF/OEF/OND military personnel who endorse a high co-occurrence of medical conditions (i.e., possible or probable TBI), pain, and psychiatric symptoms (i.e., PTSD and depressive symptoms). These findings demonstrate a specific association between PTSD re-experiencing symptoms and current self-reported pain. Thus, while previous work has highlighted the high concurrence of PTSD and pain [6,11], results from the present study suggest that PTSD re-experiencing symptoms may have a unique relationship with pain; further study will clarify possible mechanisms (e.g., anxiety sensitivity, somatization) underlying this association that may represent potential interventional targets. Given the association between TBI characteristics, self-reported pain, and specific psychiatric symptoms (i.e., depression, PTSD reexperiencing symptoms), early clinical interventions may help prevent enduring psychiatric or medical conditions; this is an important area for further study.

Indeed, the high rate of polytraumatic injury among combat Veterans highlights the challenges for effective assessment and rehabilitation efforts. In particular, pain in the context of polytrauma can have widespread effects on disability and functioning, and limited evidence exists regarding the patient factors and comorbid conditions associated with pain-related outcomes [39]. The cooccurrence of pain and psychiatric disorders, for example, has been shown to have serious adverse implications for adaptive functioning, including greater intensity of pain and affective distress, higher levels of life interference, and greater disability than individuals with an independent disorder; this result has been demonstrated in both Veteran [40] and civilian samples [19,41]. Pain symptoms may also hinder certain aspects of TBI rehabilitation; for instance, commonly used pain medications may cause cognitive side effects that interfere with the active rehabilitation process [39]. Preventative actions, such as screening pain patients for PTSD, depressive, or TBI symptoms or asking mental health and TBI patients for pain ratings, could potentially lead to earlier applications of multifocused treatments that work to alleviate the interacting physical and psychological concerns. The focus on acute risk factors may help decrease the probability that acute symptoms will persist and become chronic psychological or physical responses to trauma among postdeployment military personnel. Concurrent and/or complementary treatments may be preferred to 
sequential treatments for individual disorders; a more comprehensive approach to screening, assessment, and treatment may have greater success at alleviating the distress associated with one or more disorders, particularly if symptoms of one condition may exacerbate or maintain the other.

Several limitations to this study must be noted. Given the cross-sectional nature of the analyses, conclusions regarding causality and predictive ability of the demographic, historical, and psychosocial variables on pain symptoms are limited. Longitudinal study of symptoms and experiences over time will allow for a more complete understanding of pain risk factors and the development and maintenance of pain symptoms over time. Further, while self-report assessments can be helpful for assessing an individual's perceptions of distress and difficulties, a limitation of this assessment method is the potential bias in the respondents' self-report of their past experience and early symptoms. In particular, memory for blast exposure and pre- and postblast experiences may be affected by the length of time between injury to our evaluation, thereby introducing recall bias. Another limitation is that the PCL and CES-D were developed as screening instruments for PTSD and depression, respectively, and consequently, they have limited diagnostic specificity. However, these instruments can provide insights into a participant's subjective experience of psychiatric difficulties and hold value in the assessment of mental health concerns. Future studies will benefit from gathering clinical interview data combined with self-report data in order to more fully assess symptoms from a formal diagnostic approach as well the participants' subjective distress. More comprehensive assessment of previous trauma and blast exposure may yield additional insights regarding the association between these past exposures and current subjective symptom reports. Finally, the study sample of relatively young, primarily male, military SMs and Veterans reflects a particular composition of military personnel, and the findings may not generalize to the general population or even other military samples. While the current study had a relatively small sample size compared with other published epidemiologic studies, the smaller sample allowed us to collect more comprehensive data on the participants and to explore a wide variety of variables associated with pain. The sample was specifically recruited based on exposure to a combat-related blast, and this may represent a particular selection bias that reflects a unique composition of military personnel with regard to field duties and/or personality variables that are most likely to become exposed to explosive munitions in the field. More work is needed to better understand the risk factors and correlates of pain in diverse samples.

\section{CONCLUSIONS}

The results from this study indicated a set of correlates of self-reported current pain ratings that include older age, possible or probable mild TBI with PTA or LOC, depression symptoms, and re-experiencing symptoms of PTSD. These factors are indicative of the common polytrauma triad of TBI, psychiatric concerns, and pain found in OIF/OEF/OND Veteran samples, and results highlight the need for further work to understand the interplay of these conditions over time. The findings further the understanding of complex polytrauma injuries among military personnel by identifying specific patient characteristics and comorbidity patterns related to pain complaints. These results are important to pinpoint areas for future research and treatment development.

\section{ACKNOWLEDGMENTS}

\section{Author Contributions:}

Study concept and design: K. J. Stratton, A. B. Amstadter, D. X. Cifu, W. C. Walker.

Analysis and interpretation of data: K. J. Stratton, S. E. Hawn, A. B. Amstadter, D. X. Cifu, W. C. Walker.

Drafting of manuscript: K. J. Stratton, S. E. Hawn, A. B. Amstadter, D. X. Cifu, W. C. Walker.

Critical revision of manuscript for important intellectual content: K. J. Stratton, S. E. Hawn, A. B. Amstadter, D. X. Cifu, W. C. Walker. Literature review: S. E. Hawn.

Study supervision: K. J. Stratton.

Financial Disclosures: The authors have declared that no competing interests exist.

Funding/Support: This material was based on work supported by the VA Office of Academic Affiliations Advanced Fellowship Program in Mental Illness Research and Treatment (K. J. Stratton) and is based upon work supported in part by the Defense and Veterans Brain Injury Center and the U.S. Army Medical Research and Materiel Command Congressionally Directed Medical Research Program (grant W191ZSQ8118N6200001, W. C. Walker).

Institutional Review: The participating agencies' institutional review boards approved this study, and informed consent was obtained after the details of the study were thoroughly explained to participants.

Participant Follow-Up: The authors do not plan to inform participants of the publication of this study. 
Disclaimer: The views expressed are those of the authors and do not necessarily represent the views of the VA or any of the institutions with which the authors are affiliated.

\section{REFERENCES}

1. Hoge CW, Castro CA, Messer SC, McGurk D, Cotting DI, Koffman RL. Combat duty in Iraq and Afghanistan, mental health problems, and barriers to care. N Engl J Med. 2004; 351(1):13-22. [PMID:15229303]

http://dx.doi.org/10.1056/NEJMoa040603

2. Ramchand R, Schell TL, Karney BR, Osilla KC, Burns RM, Caldarone LB. Disparate prevalence estimates of PTSD among service members who served in Iraq and Afghanistan: Possible explanations. J Trauma Stress. 2010;23(1): 59-68. [PMID:20135699]

3. Beckham JC, Crawford AL, Feldman ME, Kirby AC, Hertzberg MA, Davidson JR, Moore SD. Chronic posttraumatic stress disorder and chronic pain in Vietnam combat veterans. J Psychosom Res. 1997;43(4):379-89.

[PMID:9330237]

http://dx.doi.org/10.1016/S0022-3999(97)00129-3

4. Jakupcak M, Luterek J, Hunt S, Conybeare D, McFall M. Posttraumatic stress and its relationship to physical health functioning in a sample of Iraq and Afghanistan War veterans seeking postdeployment VA health care. J Nerv Ment Dis. 2008;196(5):425-28. [PMID:18477887]

http://dx.doi.org/10.1097/NMD.0b013e31817108ed

5. Jakupcak M, Osborne T, Michael S, Cook J, Albrizio P, McFall M. Anxiety sensitivity and depression: Mechanisms for understanding somatic complaints in veterans with posttraumatic stress disorder. J Trauma Stress. 2006; 19(4):471-79. [PMID:16929501]

http://dx.doi.org/10.1002/jts.20145

6. Lew HL, Otis JD, Tun C, Kerns RD, Clark ME, Cifu DX. Prevalence of chronic pain, posttraumatic stress disorder, and persistent postconcussive symptoms in OIF/OEF veterans: Polytrauma clinical triad. J Rehabil Res Dev. 2009; 46(6):697-702. [PMID:20104399]

http://dx.doi.org/10.1682/JRRD.2009.01.0006

7. Shipherd JC, Keyes M, Jovanovic T, Ready DJ, Baltzell D, Worley V, Gordon-Brown V, Hayslett C, Duncan E. Veterans seeking treatment for posttraumatic stress disorder: What about comorbid chronic pain? J Rehabil Res Dev. 2007;44(2):153-66. [PMID:17551870] http://dx.doi.org/10.1682/JRRD.2006.06.0065

8. Higgins DM, Kerns RD, Brandt CA, Haskell SG, Bathulapalli H, Gilliam W, Goulet JL. Persistent pain and comorbidity among Operation Enduring Freedom/Operation Iraqi Freedom/Operation New Dawn veterans. Pain Med. 2014;
15(5):782-90. [PMID:24548466]

http://dx.doi.org/10.1111/pme.12388

9. Sayer NA, Rettmann NA, Carlson KF, Bernardy N, Sigford BJ, Hamblen JL, Friedman MJ. Veterans with history of mild traumatic brain injury and posttraumatic stress disorder: Challenges from provider perspective. J Rehabil Res Dev. 2009;46(6):703-16. [PMID:20104400]

http://dx.doi.org/10.1682/JRRD.2009.01.0008

10. Cifu DX, Taylor BC, Carne WF, Bidelspach D, Sayer NA, Scholten J, Campbell EH. Traumatic brain injury, posttraumatic stress disorder, and pain diagnoses in OIF/OEF/OND Veterans. J Rehabil Res Dev. 2013;50(9):1169-76.

[PMID:24458958]

http://dx.doi.org/10.1682/JRRD.2013.01.0006

11. Taylor BC, Hagel EM, Carlson KF, Cifu DX, Cutting A, Bidelspach DE, Sayer NA. Prevalence and costs of cooccurring traumatic brain injury with and without psychiatric disturbance and pain among Afghanistan and Iraq War Veteran V.A. users. Med Care. 2012;50(4):342-46.

[PMID:22228249]

http://dx.doi.org/10.1097/MLR.0b013e318245a558

12. Ullrich PM, Lincoln RK, Tackett MJ, Miskevics S, Smith BM, Weaver FM. Pain, depression, and health care utilization over time after spinal cord injury. Rehabil Psychol. 2013;58(2):158-65. [PMID:23713727] http://dx.doi.org/10.1037/a0032047

13. Bair MJ, Robinson RL, Katon W, Kroenke K. Depression and pain comorbidity: A literature review. Arch Intern Med. 2003;163(20):2433-45. [PMID:14609780] http://dx.doi.org/10.1001/archinte.163.20.2433

14. Gatchel RJ. Comorbidity of chronic pain and mental health disorders: The biopsychosocial perspective. Am Psychol. 2004;59(8):795-805. [PMID:15554853] http://dx.doi.org/10.1037/0003-066X.59.8.795

15. Palyo SA, Beck JG. Post-traumatic stress disorder symptoms, pain, and perceived life control: Associations with psychosocial and physical functioning. Pain. 2005;117(1-2):121-27. [PMID:16099099] http://dx.doi.org/10.1016/j.pain.2005.05.028

16. Andersson HI, Ejlertsson G, Leden I, Rosenberg C. Chronic pain in a geographically defined general population: Studies of differences in age, gender, social class, and pain localization. Clin J Pain. 1993;9(3):174-82.

[PMID:8219517] http://dx.doi.org/10.1097/00002508-199309000-00004

17. Keogh E, McCracken LM, Eccleston C. Gender moderates the association between depression and disability in chronic pain patients. Eur J Pain. 2006;10(5):413-22.

[PMID:16009583] http://dx.doi.org/10.1016/j.ejpain.2005.05.007

18. Sledjeski EM, Speisman B, Dierker LC. Does number of lifetime traumas explain the relationship between PTSD and 
chronic medical conditions? Answers from the National Comorbidity Survey-Replication (NCS-R). J Behav Med. 2008;31(4):341-49. [PMID:18553129] http://dx.doi.org/10.1007/s10865-008-9158-3

19. Villano CL, Rosenblum A, Magura S, Fong C, Cleland C, Betzler TF. Prevalence and correlates of posttraumatic stress disorder and chronic severe pain in psychiatric outpatients. J Rehabil Res Dev. 2007;44(2):167-78.

[PMID:17551871] http://dx.doi.org/10.1682/JRRD.2006.05.0052

20. Moeller-Bertram T, Afari N, Mostoufi S, Fink DS, Johnson Wright L, Baker DG. Specific pain complaints in Iraq and Afghanistan veterans screening positive for post-traumatic stress disorder. Psychosomatics. 2014;55(2):172-78. [PMID:23473449] http://dx.doi.org/10.1016/j.psym.2013.01.011

21. Walker WC, McDonald SD, Ketchum JM, Nichols M, Cifu DX. Identification of transient altered consciousness induced by military-related blast exposure and its relation to postconcussion symptoms. J Head Trauma Rehabil. 2013; 28(1):68-76. [PMID:22647964] http://dx.doi.org/10.1097/HTR.0b013e318255dfd0

22. Franke LM, Czarnota JN, Ketchum JM, Walker WC. Factor analysis of persistent postconcussive symptoms within a military sample with blast exposure. J Head Trauma Rehabil. 2014 Jul 18. Epub ahead of print.

[PMID:24695267] http://dx.doi.org/10.1097/HTR.0000000000000042

23. Melzack R. The Short-Form McGill Pain Questionnaire. Pain. 1987;30(2):191-97. [PMID:3670870] http://dx.doi.org/10.1016/0304-3959(87)91074-8

24. Scherer M, Burrows H, Pinto R, Somrack E. Characterizing self-reported dizziness and otovestibular impairment among blast-injured traumatic amputees: A pilot study. Mil Med. 2007;172(7):731-37. [PMID:17691686]

25. Gray MJ, Litz BT, Hsu JL, Lombardo TW. Psychometric properties of the life events checklist. Assessment. 2004; 11(4):330-41. [PMID:15486169]

http://dx.doi.org/10.1177/1073191104269954

26. Kubany ES. Traumatic Life Events Questionnaire (TLEQ). Los Angeles (CA): Western Psychological Services; 2004.

27. Radloff LS. The CES-D Scale: A self-report depression scale for research in the general population. Appl Psychol Meas. 1977;1:385-401.

http://dx.doi.org/10.1177/014662167700100306

28. Weathers FW, Litz BT, Herman DS, Huska JA, Keane TM. The PTSD Checklist (PCL): Reliability, validity, and diagnostic utility. Proceedings of the 9th Annual Meeting of the International Society for Traumatic Stress Studies; 1993; San Antonio, TX.

29. Asmundson GJ, Wright KD, Stein MB. Pain and PTSD symptoms in female veterans. Eur J Pain. 2004;8(4):345-50.

\section{[PMID:15207515]}

http://dx.doi.org/10.1016/j.ejpain.2003.10.008

30. Burris JL, Cyders MA, de Leeuw R, Smith GT, Carlson CR. Posttraumatic stress disorder symptoms and chronic orofacial pain: An empirical examination of the mutual maintenance model. J Orofac Pain. 2009;23(3):243-52.

[PMID:19639104]

31. Mcfarlane AC, Atchison M, Rafalowicz E, Papay P. Physical symptoms in post-traumatic stress disorder. J Psychosom Res. 1994;38(7):715-26. [PMID:7877126] http://dx.doi.org/10.1016/0022-3999(94)90024-8

32. Asmundson GJ, Coons MJ, Taylor S, Katz J. PTSD and the experience of pain: Research and clinical implications of shared vulnerability and mutual maintenance models. Can J Psychiatry. 2002;47(10):930-37. [PMID:12553128]

33. Masten AS, Narayan AJ. Child development in the context of disaster, war, and terrorism: Pathways of risk and resilience. Annu Rev Psychol. 2012;63:227-57. [PMID:21943168] http://dx.doi.org/10.1146/annurev-psych-120710-100356

34. Gironda RJ, Clark ME, Massengale JP, Walker RL. Pain among veterans of Operations Enduring Freedom and Iraqi Freedom. Pain Med. 2006;7(4):339-43. [PMID:16898945] http://dx.doi.org/10.1111/j.1526-4637.2006.00146.x

35. DoD worldwide numbers for TBI [Internet]. Silver Spring (MD): Defense and Veterans Brain Injury Center; 2014. Available from:

http://dvbic.dcoe.mil/dod-worldwide-numbers-tbi

36. Epidemiology Program, Post-Deployment Health Group, Office of Public Health, Veterans Health Administration. Analysis of VA health care utilization among Operation Enduring Freedom (OEF), Operation Iraqi Freedom (OIF), and Operation New Dawn (OND) veterans. Cumulative from 1st qtr FY 2002 through 1st qtr FY 2013 (October 1, 2001-December 31, 2012). Washington (DC): Department of Veterans Affairs; 2013 Mar.

37. Nampiaparampil DE. Prevalence of chronic pain after traumatic brain injury: A systematic review. JAMA. 2008; 300(6):711-19. [PMID:18698069] http://dx.doi.org/10.1001/jama.300.6.711

38. Sherman KB, Goldberg M, Bell KR. Traumatic brain injury and pain. Phys Med Rehabil Clin N Am. 2006;17(2): 473-90, viii. [PMID:16616278] http://dx.doi.org/10.1016/j.pmr.2005.11.007

39. Dobscha SK, Clark ME, Morasco BJ, Freeman M, Campbell R, Helfand M. Systematic review of the literature on pain in patients with polytrauma including traumatic brain injury. Pain Med. 2009;10(7):1200-1207.

[PMID:19818031]

http://dx.doi.org/10.1111/j.1526-4637.2009.00721.x

40. Outcalt SD, Yu Z, Hoen HM, Pennington TM, Krebs EE. Health care utilization among Veterans with pain and posttraumatic stress symptoms. Pain Med. 2014;15(11):1872-79. 
JRRD, Volume 51, Number 8, 2014

\section{[PMID:23432958]}

http://dx.doi.org/10.1111/pme.12045

41. Sherman JJ, Turk DC, Okifuji A. Prevalence and impact of posttraumatic stress disorder-like symptoms on patients with fibromyalgia syndrome. Clin J Pain. 2000;16(2):127-34. [PMID:10870725]

http://dx.doi.org/10.1097/00002508-200006000-00006

Submitted for publication April 24, 2014. Accepted in revised form July 7, 2014.
This article and any supplementary material should be cited as follows:

Stratton KJ, Hawn SE, Amstadter AB, Cifu DX, Walker WC. Correlates of pain symptoms among Iraq and Afghanistan military personnel following combat-related blast exposure. J Rehabil Res Dev. 2014;51(8):1189-1202. http://dx.doi.org/10.1682/JRRD.2014.04.0111

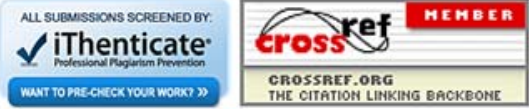

